
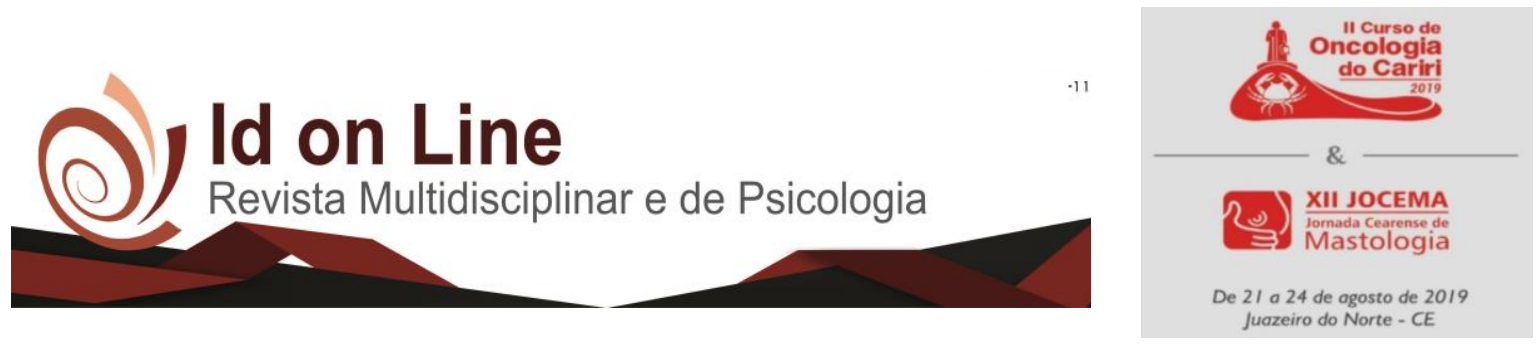

DOI: 10.14295/idonline.v13i46.2005

Resumo

\title{
PREVENÇÃO DO CÂNCER DE MAMA NA REGIÃO DO CARIRI: A LITERATURA DE CORDEL COMO FERRAMENTA PEDAGÓGICA E CULTURAL
}

\author{
Maria Andrezza Gomes Maia ${ }^{1}$, Pedro Walisson Gomes Feitosa ${ }^{1}$, Ítalo Constâncio de Oliveira ${ }^{1}$; \\ Sally de França Lacerda Pinheiro ${ }^{2}$
}

Introdução: $O$ câncer de mama representa a principal causa de morte por câncer em mulheres brasileiras. Os hábitos de cuidados com a saúde possuem relação direta com as representações epidemiológicas. A educação em saúde continua a ser objeto de reflexão crescente por parte de políticos, instituições e mesmo de autores isolados em artigos de literatura específica. Nesse interim, considerando que a Literatura de Cordel já fez parte das nossas tradições, é importante tanto no resgate de nossas raízes culturais tanto como instrumento de despertar o senso crítico e histórico das manifestações populares, sendo um inovador e eficiente método pedagógico de educação em saúde. Objetivo: Relatar uma experiência de educação em saúde na prevenção do câncer de mama na região do Cariri Cearense. Método: Foi realizado no mês de outubro de 2018 um encontro acadêmico para elaboração de um cordel no tema proposto, tendo por resultado a produção "Um laço rosa". O cordel foi digitalizado para publicação nas mídias digitais do projeto e impresso, no total de 150 cópias, no formato de livreto para distribuição em encontros de educação em saúde. Resultados: As publicações nas mídias digitais do projeto representaram, até julho de 2018, um alcance de 971 perfis digitais, expressando 80 reações e 14 compartilhamentos. A educação por intermédio das mídias vem se desenvolvendo no mundo inteiro com o objetivo de formar usuários criativos e críticos, sendo incorporada também ao processo de educação popular em saúde. Ainda em outubro de 2018, a produção foi tema de debate no encontro "Vamos falar sobre câncer de mama?", um evento realizado pelo projeto de extensão "ProGest" e pelo projeto de cultura "Cordel, Café, Ciência e Saúde", ambos da Universidade Federal do Cariri. Nesse encontro o cordel foi recitado na abertura do evento, dando início ao debate composto por profissionais da saúde e acadêmicos de Medicina. Dessa forma, esta intervenção corrobora com um dos objetivos centrais da educação contemporânea de produzir um contingente maior de profissionais tecnicamente qualificados e com atributos sociais e humanos adequados para lidar com as necessidades de saúde dos diferentes segmentos da população. Conclusão: Concluímos que a Literatura de Cordel contribui com a promoção da saúde pela prevenção do câncer de mama, uma vez que esta possibilita maior acessibilidade ao conhecimento dos cuidados com a qualidade de vida da mulher na região do Cariri.

Palavras-chave: câncer de mama; literatura de cordel; educação em saúde.

${ }^{1}$ Discente da Universidade Federal do Cariri;

2 Docente da Universidade Federal do Cariri. 


\section{Referências:}

FRAZÃO, Amanda; SKABA, Márcia Marília Fróesvargas. Mulheres com Câncer de Mama: as Expressões da Questão Social durante o Tratamento de Quimioterapia Neoadjuvante. Revista Brasileira de Cancerologia, Rio de Janeiro, v. 3, n. 59, p.427-435, 22 maio 2013.

INSTITUTO NACIONAL DE CÂNCER (Brasil). Estimativa 2010. Incidência do Câncer no Brasil. Rio de Janeiro: INCA, 2009.

SOUZA, Luana Rafaela dos Santos de; PASSOS, Virginia de Oliveira Alves. Literatura De Cordel: Um recurso pedagógico. Revista Científica da Fasete, Bahia, v. 2, n. 5, p.75-90, 2018.

SALCI, Maria Aparecida et al. Educação Em Saúde E Suas Perspectivas Teóricas: Algumas Reflexões. Texto \& Contexto- Enfermagem, Florianópolis, v. 1, n. 22, p.224-230, 10 jul. 2012. 